This item was submitted to Loughborough's Research Repository by the author.

Items in Figshare are protected by copyright, with all rights reserved, unless otherwise indicated.

\title{
Revisiting the trajectory of IT implementation in organisations: An IT culture perspective
}

\section{PLEASE CITE THE PUBLISHED VERSION}

http://dx.doi.org/10.1108/ITP-09-2015-0217

\section{PUBLISHER}

(C) Emerald

VERSION

AM (Accepted Manuscript)

\section{PUBLISHER STATEMENT}

This work is made available according to the conditions of the Creative Commons Attribution-NonCommercialNoDerivatives 4.0 International (CC BY-NC-ND 4.0) licence. Full details of this licence are available at: https://creativecommons.org/licenses/by-nc-nd/4.0/

\section{LICENCE}

CC BY-NC-ND 4.0

\section{REPOSITORY RECORD}

Abubakre, Mumin Adetunji, M.N. Ravishankar, and Crispin Coombs. 2019. "Revisiting the Trajectory of IT Implementation in Organisations: An IT Culture Perspective". figshare. https://hdl.handle.net/2134/22200. 


\title{
Revisiting the trajectory of IT implementation in organisations: An IT Culture Perspective
}

\begin{abstract}
Purpose - Organisational implementations of information technology (IT) normally fail due to cultural forces that inhibit the usage levels required to facilitate successful IT implementation. This paper explores IT implementation from an IT Culture perspective (Leidner and Kayworth, 2006). In particular, it identifies and follows the trajectory of IT culture archetypes that emerge during the implementation process and further investigates their role in facilitating successful IT implementations.
\end{abstract}

Design/methodology/approach - This research adopts the qualitative single case study approach and draws on the implementation of a management information system (MIS) in a Nigerian global bank.

Findings - The findings illustrate three different IT culture archetypes and provide insights into their dynamic nature. The progressive weakening of two IT culture archetypes and the corresponding strengthening of the third archetype shows how initial vision conflicts can get transformed into vision agreements.

Originality/value - This paper extends the IT Culture perspective by illustrating how a congruence relationship between IT cultures and IT artefacts can be fostered. The paper shows how diverse IT cultures can develop reasonably quickly in line with initial user experiences of a system. When IT cultures are aligned with the values embedded in IT, positive engagement and usage of the technology results, strengthening the presence of embracing IT cultures.

Keywords - IT implementation, IT culture, IT artefact, Vision conflict. 


\section{Introduction}

Successful information technology (IT) implementations remain a critical challenge for many organisations. Consequently, IS research has argued that much can still be learnt from studies of IT implementation and usage (e.g. Venkatesh et al., 2012; Williams et al., 2009). Culture theory has been applied in IS research to help understand how organisations make sense of the implementation, usage and integration of IT into organisational practices (e.g. Ravishankar et al., 2011; Rivard et al., 2011). These aforementioned studies provide valuable insights into how IT is incorporated into organisational structures and processes. They highlight a gradual IT acculturation process through which the meanings and purposes of work activities are socially reconstructed. In essence, organisational groups undertake a cultural learning process resulting from the introduction to, and interactions with, IT (Walsh et al., 2010). More importantly, these culture-IT studies provide insights regarding how different organisational groups may respond to and enact IT in their everyday work. Unfortunately, many of the actions of these organisational groups towards IT may lead to unsuccessful IT implementations.

Extant culture-IT studies have largely explored the implications of organisational culture or subculture on IT implementation, disregarding the implications of an individual's cultural disposition toward IT. A consideration of individual cultural dispositions toward IT highlights the ubiquity of IT in an IT user's everyday life, blending their work and social practices to form an IT culture (Walsh, 2014). The IT culture perspective helps us understand an individual's social practices when they interact with IT. These social practices are influenced by the individual's personal needs and motivations to use technology rather than the organisation's or subgroup's needs and motivations for technology use (Leidner and Kayworth, 2006; Walsh et al., 2010). Thus, by understanding a person's IT needs and motivations, the IT culture concept can help explain the complexities of individuals' actions and behaviours toward IT, which are vital to understanding how IT implementations can be managed.

Considering that the manifestation of an IT culture is also dependent on an individual's own perceptions of the technology, the IT artefact also plays a role in the manifestation of the IT culture during the technology implementation process. Orlikowski and Iacono (2001) echoed this point by suggesting that IT artefacts are not 'black boxes' with docile roles, but play unstable and interdependent roles during an IT implementation process. The IT artefact role 
is facilitated by the values embedded in the technology (Koch et al., 2013; Leidner and Kayworth, 2006). For example, if a management information system (MIS) was designed to ensure timely and accurate production of management reports, values such as efficiency and reliability must be embedded into the system for users to perceive the value of using the system.

Combining the role of the IT artefact with the IT culture perspective highlights a relationship between an individual's IT culture and the values embedded in an IT. It is vital that users' IT cultures and the values embedded in an IT are congruent to facilitate continued usage of the technology and successful implementation. If these two sets of values are inconsistent a vision conflict may occur that could cause IT failure (Leidner and Kayworth, 2006). Thus, the overall aim of our research is to understand how the relationship between individuals' IT culture and the values embedded in an IT could facilitate the achievement of a successful IT implementation. Motivated by these concerns, we address the following research questions: (1) What IT cultures can be identified during the implementation of an IT? (2) How does IT culture influence the successful implementation of IT?

The above research questions are explored in the context of a MIS that was implemented in a Nigerian global bank. The research is based on a single qualitative case study. While attempting to explain how an organisation could achieve successful IT implementation from our case, we also propose the 'vision agreement' concept. The 'vision agreement' concept reveals that during IT implementation, IT cultures and the values embedded in an IT can become congruent, which is vital for achieving successful IT implementation. Our 'vision agreement' concept extends existing research by showing how a 'vision conflict' (Leidner and Kayworth, 2006) relationship between IT culture and values embedded in an IT can be overcome. Practically, understanding the 'vision agreement' concept can shed light on how managers can engender positive IT usage by ensuring that values embedded in IT are consistent with users' IT cultures. This can help attain IT success and achieve organisational efficiencies. The next section reviews the theoretical foundation for our work. Subsequently, we discuss our research methods. Later sections describe our case findings, discussion and conclusions. 


\section{Theoretical Foundation}

\section{IT Implementation}

IT implementation studies are concerned with exploring how successful IT use can be achieved when implemented into an organisation's existing systems and processes. Several seminal works have captured different dimensions of IS success measurement (e.g. Delone and Mclean, 2003) and different categories of IT failure (e.g. Lyytinen and Hirschheim, 1987). Scholars have also presented long lists of critical success factors necessary to avoid IT failure (Fortune and White, 2006). Wagner and Newell (2011) argue that although numerous tactics can be used to overcome IT failure and encourage successful implementation, longterm viability hinges on users' enhanced and continued usage of the technology. In many cases, IT failure occurs due to perceived threats to users, such as control or power loss (Markus, 1983), deskilling (Alvarez, 2008) and distrust of IT objectives (Lyytinen and Hirschheim, 1987). This challenge is compounded by the emergence of distinct organisational groups that hold different values and different expectations and behave differently towards the implemented IT. Some groups may find that IT usage satisfies their needs and are therefore motivated to interact and use it, while the reverse may be true for groups whose IT needs are not met (Ravishankar et al., 2011).

The exploration of users' behaviours and reactions during IT implementation points to the crucial role played by culture during IT implementations. In their extensive review of the literature, Leidner and Kayworth (2006) highlight that IS scholars have adopted culture theory to explain how and why cultural forces may influence social groups' behaviour and reactions toward IT at a national level (see Png et al., 2001; Jarvenpaa and Leidner, 1998), organisational level (see Alavi et al., 2006; Ruppel and Harrington, 2001) and at the subgroup level (see Ravishankar et al., 2011; Von Meier, 1999). While these different tiers of cultural analysis have provided rich insights, less attention has been given to studying how culture at an individual level (Leidner and Kayworth, 2006; Walsh, 2014) influences implementation. The study of IT implementation at the individual level of culture has been posited to understand the values that an individual ascribes to IT. The argument for the reinterpretation of culture at an individual level is based on the principle that an individual espouses a subset of IT-related values and assumptions (his/her IT culture), which are distinct from the cultural dispositions towards IT found at national, organisational and subgroup levels. 


\section{Culture at the Individual Level and IT Culture}

Straub et al. (2002) identifies two related paradigms, social identity theory (SIT) and the virtual onion model, to conceptualise culture at the individual level. They use the virtual onion metaphor to suggest that in line with the layers of the virtual onion, an individual belongs to many subcultures, having an affiliation to several social groups at the national, religious, organisational, professional and ethnic levels. Walsh et al. (2010) underline the interplay between individual culture and group subcultures by suggesting each individual is a unique product of various interacting identity layers that evolve and intermingle.

Straub et al.'s (2002) conceptualisation of culture at the individual level resonates with the interpretivist/metaphorical perspective of culture (see Meyerson and Martin, 1987; Smircich, 1983). This perspective is in contrast to Schein's (1985) functionalist perspective which assumes culture can be managed in an integrative way. Studies that adopt an interpretivist/metaphorical perspective of culture suggest that culture should be studied at multiple levels. For example, Martin (1992, 2002) proposes that culture should be considered from the perspectives of integration, differentiation and fragmentation, so as to clearly capture its complex and multifaceted nature. Examining culture at the individual level resonates with Martin’s (2002) differentiation perspective of culture, since an individual's cultural attributes are a unique combination of group values that are interpreted based on the his/her different needs and motivations (Walsh et al., 2010). So, insights from SIT, the virtual onion model and the differentiation perspective of culture would suggest that individuals' IT culture (i.e. the values they attribute to IT and their assumptions about IT) is closely linked to their particular needs and the degree to which the concerned IT system satisfies such needs (Walsh et al., 2010). As explained by Walsh (2014), human needs are antecedent to values and assumptions and are appropriate to understand IT culture given that individuals are known to have needs that diverge from their groups (Gallivan and Keill, 2003). Factors like education, experience and skill sets explain how these needs are formed (Post et al., 1999).

Walsh (2014) argues that the IT culture perspective helps explore individual needs (e.g. primary, power, affiliation and self-accomplishment) and motivations (intrinsic and extrinsic) that are fulfilled (or not) by IT usage. Thus, the IT culture concept can explain how and why individuals with similar IT-related values (i.e. needs and motivations) form a specific IT culture archetype. In their study of two organisations, Kaarst-Brown and Robey (1999) identified archetypal patterns that comprised five IT culture archetypes; the revered, 
controlled, demystified, integrated, and fearful IT cultures. Their findings suggest the IT culture archetypes develop due to the influence of contextual factors (individual, organisational and societal). These contextual factors may influence enculturation processes that include individual and group socialisation, knowledge-set attainment, leadership and myths. In their study, the salience of different IT cultures led to conflicts over IT direction, innovation, and integration of IT with business strategy. Building on Kaarst-Brown and Robey's (1999) study, Walsh et al., (2010) propose a framework that shows how individuals with similar IT needs during IT usage came together to form specific IT culture archetypes. They define 'global' IT needs as the overall daily need to use IT in all aspects of an individual's life beyond just practical needs e.g. use of the internet and social media; 'contextual' IT needs as the need to use IT to complete tasks in a work context; e.g. use of personal computers in the workplace; and 'situational' IT needs as the need to use a specific IT to achieve a certain tasks, e.g. the need to use a MIS to efficiently produce management reports.

The literature also indicates that individual needs and motivations to use IT can be used to identify and distinguish IT culture archetypes. In their study Walsh et al., (2010) identified nine IT culture archetypes: constrained; dangerous; disciplined; disenchanted; dodger; frightened; interested; passionate; and studious. They also revealed that the IT culture archetypes changed or shifted over time. Interactions between archetypes can result in one archetype inhabiting the other and becoming the dominant archetype. Such a 'culture creep' highlights the possible dynamic and interacting nature of IT culture archetypes. Walsh et al.'s (2010) theorizing of IT culture follows Leidner and Kayworth's (2006) description of IT culture as comprising of IT values, the particular values a group attributes to IT. IT cultures could also develop when individuals make specific assumptions about IT systems (KaarstBrown and Robey, 1999). Leidner and Kayworth (2006) suggest that understanding these IT values and assumptions will provide deeper insights into how groups perceive, and ultimately respond to IT-based change. They posit three types of cultural conflicts that arise during IT implementation: contribution, system and vision conflicts. Contribution conflict refers to inconsistencies between users' IT culture and their group's culture. System conflict occurs when users perceive contradictions between their group's culture and the values embedded in IT. Finally, vision conflict (which we also observed in our empirical data) occurs due to inconsistencies between users' IT culture and the values embedded in IT. 
In a recent study, Guzman and Stanton (2009) conceptualised IT culture somewhat narrowly as the culture of IT professionals, which is distinct from the culture of a business group that utilises the IT . Their conceptualisation of IT culture best fits an IT group since they are likely to have similar natural dispositions towards IT, and therefore would have similar interpretations of the IT. However, this conceptualisation of IT culture is less likely to fit a business group where members normally perceive interactions with IT as only necessary to support and complete business based tasks. They may not consider interaction with IT as their primary task (Abubakre et al., 2014). As we demonstrate in our empirical sections, IT culture differs from values shared by an occupational or organisational group in that members within a group, despite having a shared culture may have different individual assumptions and interpretations about a given IT system. In this sense, our focus is on how individual IT values and assumptions, which are different from dominant organisational and subcultural orientations, influence IT implementation. We now turn to the IT artefact and the influence values embedded in IT and assumptions about IT may have on the IT implementation process.

\section{Role of IT Artefact in IT Implementation}

Previous IS research has explored the relationship between a group's perceptions of IT and the IT artefact itself (e.g. Markus and Robey, 1988; Orlikowski and Iacano, 2001). Orlikowski and Iacano (2001) theorise that technology artefacts can be seen as tools for labour substitution, enhancing productivity, information processing, and changing social relations. Orlikowski and Iacono's (2001) conceptualisation of IT artefacts as tools is consistent with Davis's (1989) work on IT adoption models (i.e. the Technology Acceptance Model). Davis (1989) suggests that IT artefacts are productivity tools that help shape users intentions and behaviours, based on the perceived usefulness (e.g. improved performance) they expect from the technology. Nonetheless, Davis's (1989) conceptualisation of an IT artefact is simplistic because it assumes that individuals' or organisations' interactions with the IT artefact are discrete, and that the entities are independent of each other (Al-Natour and Benbasat, 2009). Davis' (1989) function-based view of the IT artefact can be contrasted with Orlikowski and Scott's (2008) view. Orlikowski and Scott (2008) suggest that the application of IT is embedded within structure(s), and interdependent with structure(s) for enabling and supporting task(s). This embedded view of IT highlights that IT artefacts are not just practical tools, but afford two-way interactions/communication between user groups and the IT to enable social presence. In their study of online shopping, Qiu and Benbasat (2005) suggest 
that an IT artefact (a 3D avatar as the humanoid representation of a customer service representative), embedded in its environment (e-commerce website) can serve as a communication intermediary between shoppers and the organisation. This intermediary can enrich customers' interactions with the website, thereby improving customers' online shopping experience. However, an IT artefact can only be truly embedded within its environment if the technology supports the values of the ecosystem within which it is embedded. This is vital because an IT artefact is non-neutral in nature and symbolises different values to different user groups, who in turn have their own specific values (Leidner and Kayworth, 2006). Therefore, values that would align with a user groups’ work values and practices needs to be embedded into the IT artefact because inconsistency between these two sets of values may lead to conflicts (Leidner and Kayworth, 2006).

In sum, to achieve successful IT implementations, an understanding of how IT cultures and the values embedded in a specific type of IT artefact can be aligned is required. The next sections of the paper further develops these arguments through a qualitative case study, which explores the relationship between IT cultures and the values incorporated into a system. In particular, the study analyses the emergence of three different IT cultures, their trajectories and influence on the IT implementation process.

\section{Methods}

Our analytic induction approach was based on a single-case-study design. The single-case study enabled us make sense of data, without running the risk of oversimplifying and helped to provide a rich description of the investigated phenomenon (Siggelkow, 2007). The exploratory nature of a case-study approach allowed us to provide fresh insights into the IT implementation process from a IT culture perspective. Rather than treating the IT artefact as a static bundle of features, the design of which directly affects how users evaluate it, we viewed each interaction a user had with an IT as the basic unit of analysis that determined adoption and usage behaviours. In other words, we did not assume that different individuals utilised IT in the same way, or that an individual would utilise the technology in a constant manner during the implementation process.

\section{Research Context}

We studied an organisation called Alpha Bank (a pseudonym). Alpha Bank is a Nigeria-based global bank operating in 22 countries including the UK, France and the US. We chose Alpha Bank for theoretical sampling reasons (Patton, 1990). Alpha Bank is a multi-billion-dollar 
multinational bank, which employs over 13,000 full-time staff worldwide and provides financial services to over 7.2 million customers. The bank, as a leading financial services institution, uses IT extensively and thus proved an ideal site to explore IT cultures and the organisational management of IT implementation. The studied IT, a robust enterprise MIS called 'Maxim' (a pseudonym) was developed in-house by a dedicated management information (MI) team made up of IT expatriates from India and local IT staff, who were supervised by an IT expert who was a former member of Citibank, London. Maxim was a three-tier software architecture system that was presented as a revolutionary tool capable of speeding up the process of complex data analysis for the generation of sophisticated management reports.

\section{Data collection}

The first author undertook the data collection. Prior to the data collection, the bank was contacted via a top executive in its finance group, who granted us formal approval for the study. The fieldwork began by interviewing IT project managers, while subsequent interviewees were selected using a snowball sampling procedure (Patton, 2002). This sampling approach allowed the identification of the most knowledgeable informants regarding our investigated research phenomenon, based on the expertise and experience of the IT project managers. This sampling strategy enabled rich descriptions and minimised the risk of introducing bias into the sample.

An interview schedule was developed based on existing literature on culture, IT implementation and IT artefacts. Although not rigid, an interview guide comprising of a standard set of questions was used to achieve consistency across all interviews. This guide helped to maintain focus on the key research interests of the study. Interview questions addressed each informant's background and their involvement and understanding of the implementation of Maxim This questioning enabled us to explore Alpha bank members' perceptions of Maxim and how it related to their values, assumptions and priorities. Interview questions also addressed how informants perceived senior management's and members' roles and responsibilities during the implementation of the project. Probing questions were asked when informants were unclear or ambiguous in their answers and examples were requested to support informants' claims.

In total, 77 semi-structured field interviews were conducted at Alpha bank's headquarters in Lagos, Nigeria (see Table 1). The interviews lasted from 30 to 75 minutes in length and 74 
interviews were tape-recorded and transcribed. Three interviewees refused to be taperecorded. Detailed notes were made immediately after these three interviews. Follow-up interviews were conducted via telephone, email and BlackBerry messenger chat to help clarify comments made by the interviewees. The interviews were conducted between December 2010 and February 2013.

\begin{tabular}{lcccc}
\hline Group & $\begin{array}{c}\text { Senior-level } \\
\text { managers }\end{array}$ & $\begin{array}{c}\text { Middle-level } \\
\text { managers }\end{array}$ & $\begin{array}{c}\text { Low-level } \\
\text { managers }\end{array}$ & Total \\
\hline Finance & $5(2)$ & $11(9)$ & $6(5)$ & $22(16)$ \\
Operations & $3(1)$ & $7(4)$ & $7(2)$ & $17(7)$ \\
Information & $3(2)$ & $3(2)$ & $2(3)$ & $8(7)$ \\
Technology & $11(7)$ & $21(15)$ & $15(10)$ & $47(30)$ \\
Total & & & & \\
\hline
\end{tabular}

Note: Numbers in brackets refer to the number of follow-up interviews conducted via telephone, e-mail or BlackBerry messenger chat within each interviewee category.

Table 1: Summary of interviews and interviewees

The interviewees belonged to the finance, IT and operations subgroups within Alpha bank's headquarters in Lagos. The sample consisted of informants from diverse backgrounds (West and South Africa, Southern Asia and Western Europe). They included database administrators, software engineers, senior software engineers, project managers, business unit heads, group heads and some executive management members. The interview sample also comprised senior representatives (strategic, tactical and operational managers) of the bank, because they were assumed to be the most knowledgeable informants in the bank. There were two further benefits of interviewing informants across multiple levels. First, it provided representativeness and consistency in informants' descriptions of their experiences with Maxim. Second, it allowed triangulation through the comparison of views expressed by managers across different levels. Yin (2009) recommends three tactics to confirm construct validity in case study research: use multiple sources of evidence; establish a chain of evidence; and have key informants review a draft case study report. We followed these recommendations by supplementing the interviews with unobtrusive observations and drawing on additional data sources e.g. an internal Maxim business case file, memos regarding IT implementation policies and e-mail correspondence which reflected members' 
responses to Maxim's implementation. Reviewing data across multiple different sources ensured consistent interpretation of key events and enhanced the richness of our findings, satisfying the first requirement for construct validity. To satisfy the other two requirements, we took the following steps: (1) Established a chain of evidence by developing a database of the audio recorded and transcribed interviews, detailed notes of the unrecorded audio interviews and collections of email and BlackBerry messenger correspondence. Following this case study protocol provided a strong chain of evidence to link our data with our findings, increasing the reliability of our study. (2) Case study report drafts were reviewed by a senior Finance Executive, the Head of Business Operations and a Senior Programmer in the IT Group. Their appraisals resulted in some minor changes to the draft report but feedback was consistently positive and confirmed our findings.

\section{Data Analysis}

In line with analytic induction, the analysis began with a data-reduction process to examine the large volume of transcripts and notes. This data-reduction method enabled the identification, categorisation and description of the themes that emerged from the data. The qualitative analysis software QSR NVivo 8 was used to code the data. After reading the interview transcripts several times, similar statements were grouped together that best described informants' views, actions and behaviours' toward Maxim during the implementation process. We created six categories: "stakeholder types", "implementation process”, “values members ascribed to Maxim”, “perceived values embedded into Maxim”, “users' reactions” and “impact on Maxim implementation”. The resulting set of categories and examples of codes included in each category are listed in Table 2.

\begin{tabular}{|c|c|}
\hline Category & Example Codes \\
\hline Stakeholder types & $\begin{array}{l}\text { Senior Management; IT; Finance and } \\
\text { Operations groups }\end{array}$ \\
\hline Implementation process & $\begin{array}{l}\text { Design and development of Maxim; } \\
\text { Users' initial experiences of Maxim; } \\
\text { Users' engagement with Maxim } \\
\text { following the intervention of the IT } \\
\text { group }\end{array}$ \\
\hline $\begin{array}{l}\text { Values ascribed to Maxim/Assumptions } \\
\text { about Maxim }\end{array}$ & $\begin{array}{l}\text { Reliable and accurate, complicated, } \\
\text { unreliable and inaccurate }\end{array}$ \\
\hline Perceived values embedded into & Reliability and integrity of data \\
\hline
\end{tabular}


Maxim

Users' reactions

Impact on Maxim implementation
Acceptance; Resistance

Helped; impeded

Table 2: Categories and codes created during data analysis

Upon completion of the data coding, the application of the coding scheme to the data was reviewed by the co-authors. This review involved the co-authors independently examining a sample of coded transcripts and then discussing coding decisions to reach agreement. Data analysis proceeded through several iterations in this manner. In addition, during these iterations the data was continually reassessed to evaluate the degree of agreement among users' perceptions of the assumptions and values they ascribed to Maxim, the perceived values embedded into the technology and the relationship between these two sets of values. This was to ensure data interpretations were accurate and to check for possible coding bias. We revisited the literature to synthesise our analysis with existing studies. Revisiting the literature was particularly useful because it permitted us to compare the emergent themes from our data with the literature and to identify a suitable theoretical lens. We found Walsh et al.'s (2010) conceptualisation of IT culture based on IT needs and IT motivation to be a useful lens to interpret and identify the values users ascribed to Maxim. This allowed us to understand users that exhibited similar behaviours towards Maxim, highlighting how and why individuals could form a specific IT culture archetype. We used Leidner and Kayworth’s (2006) conceptualisation of vision-conflict to help us understand the relationship between the values and assumptions users' ascribed to Maxim and the perceived values embedded in the technology during the implementation process. This approach revealed how users' relationship with Maxim changed over the course of the implementation. Thus, we were able to study user transitions from one IT culture archetype to another, thereby illustrating the dynamic nature of the identified IT culture archetypes.

Our inductive analysis strategy also enabled us focus on the degree of saliency of each of the identified IT culture archetypes. The degree of saliency was determined by rating particular users' actions and behaviours. Informants' indications of similar behaviours and attitudes towards Maxim having a highly significant or significant impact on the implementation (i.e. design and use) of the technology were coded as salient, while suggestions of similar behaviours and attitudes towards Maxim having a less significant or insignificant bearing on the implementation were coded as latent. This study did not involve any sensitive ethical 
issues. However, because the research involved direct personal inter-relationships, i.e. interviewing of informants, ethical issues needed to be considered (Walliman, 2008). The research was conducted in line with the ethical guidance regulations for social research at the authors' university. All interviewees were provided with an information sheet and consent form to sign and were made aware that they could withdraw their data at any time. Interviewees were assured that the interview transcripts would be kept confidential and all identifying information of interviewees and the organisation were removed.

\section{Findings}

\section{IT Implementation in Alpha Bank}

Maxim was intended to replace old methods of performing organisational tasks. Its design and development was led by the IT group and was primarily based on the information needs of the finance and operations groups. Representatives of these two groups had also explained their particular requirements to the IT group during the design process. The Maxim system was introduced to the two groups following a series of awareness and promotional campaigns, user-acceptance tests, and a training program for the users.

\section{IT culture archetypes}

Within and across the operations and finance groups, we found three fundamentally different types of immediate responses to Maxim. Each type of response reflected a specific set of beliefs and assumptions about what Maxim could and could not do. Given that they each illustrated a particular attitude and approach to Maxim we labelled these three responses as representative of three different IT culture archetypes: embracing, confused and complaining.

\section{Embracing IT Culture}

One set of users within the operations and finance groups took an active and welcoming approach to Maxim. They embraced most of its features and were extremely positive about the benefits of the system. We may thus characterise this cluster of users as belonging to an embracing IT culture.

With my experience and my qualification in terms of MIS, I think there is nothing I cannot do on Maxim. (Head of Finance Group)

Members in the embracing IT culture not only began using the basic features of Maxim, but also demonstrated enthusiasm and curiosity about the other possibilities of the system. 
Having an engineering background, sometimes I feel things can be done easily. I often ask the IT group...can we tweak Maxim in a way that will give me the report I want? I know what Maxim is supposed to accomplish. (Senior Analyst - Balance Sheet \& Market Risk Management, Finance Group)

I sat with the team to understand what they were doing and we came up with an idea as to how we can interface other databases to Maxim. (Head of e-Channels - operations group)

They also felt that Maxim was an innovative system that would help the bank improve its competitiveness. They did not think that there would be any opposition to its use within their respective groups.

There is really no resistance because Maxim enhances your job and makes things easier and faster. It is a positive tool and everybody that is forward thinking will definitely accept and embrace it. (Senior Analyst - Balance Sheet \& Market Risk Management, Finance Group)

Informants explained that since there was an expectation that Maxim would be used in a routine manner they undertook measures to achieve the objective of fully implementing the technology. Their direct and hands-on approach of engaging extensively with Maxim had an additional positive effect. They were able to discover and work with some of Maxim's more advanced features. Informants in the embracing IT culture noted that their increased use of Maxim helped them get more out of the system.

My increased interactions with Maxim have actually helped...you see other things that can be done, other ways of reporting, how to generate reports with flexibility. I can see that Maxim is superior when it comes to producing reports. (Senior Analyst - Balance Sheet \& Market Risk Management, Finance Group)

I get more data out of Maxim... I now extract with success, using Maxim to extract all data sources from the core banking application and servers. (Head of e-Channels, Operations Group)

In short, this group of individuals embraced Maxim because they believed that the system simplified a wide range of everyday tasks. They welcomed Maxim's introduction and reported that they enjoyed working with, and learning about the technology. In other words, soon after Maxim's implementation the embracing IT culture began using it in a routine manner in order to generate and analyse large volumes of management information. Members of the embracing IT culture believed that their vision of an ideal system was perfectly manifested in Maxim. We might therefore suggest that 'vision agreement' - alignment between the IT development team's view of the system and the user group's view of the 
system as reliable and accurate - was evident in the embracing IT culture.

Confused IT Culture

A second set of users, unlike the embracing cohort, found Maxim complex and were extremely reticent to use the system to perform any advanced data analysis. We found such users in the operations and finance groups. They were unsure about Maxim and explained that although they used some basic features, they remained confused by many of the system's functionalities. We may thus describe this set of users as manifesting the characteristics of a confused IT culture. The empirical material provided several instances of how this set of users could not understand how Maxim could be integrated into the bank's existing processes. For instance:

We had problems getting people to map properly for most of the General Ledger (GL) case; people could not understand how it works and how their applications would feed into Maxim. They were confused and were not really motivated to engage with it. (Senior Financial Analyst - African Subsidiaries, Finance Group)

As highlighted by the aforementioned data, this group of individuals were unclear about the purpose of Maxim and were unsure about how to engage with the technology. They did not perceive a need to fully engage with the system, choosing to use only the simplest features and ignoring the advanced ones. Thus, members of the confused IT culture did not fully employ the system in their everyday activities.

I use it but sparingly. It is new and I don't really understand it well enough, maybe I am used to getting our reports from other software applications, but not Maxim. Business Operations Support (Operations Group)

Overall, this set of individuals was not fully motivated to engage with Maxim because they did not clearly understand the need for the system. Their limited engagement meant that they produced very few management information reports through Maxim, leading to low usage of the system in the immediate aftermath of its introduction to the operations and finance groups. Thus, although members of the confused IT culture valued accurate and reliable IT systems, their initial experience of Maxim pointed to 'vision conflict', i.e. their belief that Maxim is a complex and hard to understand system was at odds with the values attributed by the IT group to the system.

\section{Complaining IT Culture}

A final set of users in the operations and finance groups evaluated Maxim negatively soon after its introduction. They were quick to judge the system as poor and explained that they 
had no motivation to employ Maxim in their everyday work. These users' complained that the system presented erroneous information and that it was incapable of performing accurate financial analysis. A central characteristic of their immediate response to Maxim was their articulation of a long-list of complaints about the system's weaknesses and failings. Hence, we may characterise this particular set of users in the operational and finance groups as forming a complaining IT culture.

At first when I first started, I noticed that there are some things that are so basic that you thought Maxim would do and you noticed it is not working as expected, errors and omissions in the figures; you will be disappointed, so you can't use it. Financial Controller (Finance Group)

Similarly, the complaining members in the operations group felt that their business requirements had not been fully taken into account during Maxim's design. Therefore, they refused to use the system.

I do not like Maxim because my requirements were not considered during its design. That's why I do not use it. Information that you need to do analysis are not forthcoming when trying to use Maxim. It does not seem to work. It affects performance and I find it frustrating. (Head of Business Operations -Operations Group)

Broadly, members of the complaining IT culture refused to engage with Maxim because of its perceived weaknesses. They believed that their particular demands had been ignored during the design and development phases. They complained vociferously about the system soon after its roll-out. Such expressions of frustrations are consistent with previous studies that have highlighted conflicts and resistance during the post-implementation phases of an IT system (e.g., Ravishankar et al., 2011; Rivard et al., 2011). Like the confused IT culture, these initial responses point to the presence of a 'vision conflict' (Leidner and Kayworth, 2006) between the formal organisational visualisation of Maxim and the particular individual-level assumptions of the complaining IT culture.

\section{Strengthening the IT artefact and training the users}

The IT group, which developed Maxim had focused their energies on building a robust system. They had worked to ensure that the system was reliable, accurate and efficient to use.

When compared to other tools, Maxim allows users to be more productive in their data analysis and it generates reliable management reports. Head of IT Group

Members of the IT group emphasized that they had conceptualised Maxim as a robust system, which would have high levels of integrity and reliability built into it (values close to 
the hearts of many of the bank employees). From an IT culture perspective, the IT group can be seen as attributing values of integrity and reliability to Maxim. They explained that integrity and reliability were particularly important for the operations and finance groups, given that they often dealt with large sums of money and sensitive issues of a confidential nature. Therefore they (the IT group) designed Maxim to be a highly accurate system and felt that it was a good choice for the bank. In other words, there was a deliberate and clear focus on achieving efficiencies and maintaining the integrity of data. However, the IT group acknowledged that some teething troubles (e.g. unreliable data in the some modules, clunky user interfaces, issues of speed and problems with data presentation) surfaced just after the system was implemented. They knew that these problems had led to unhappiness in parts of the operations and finance groups. At this stage, the IT group worked proactively with a select group of end-users and conducted extensive tests on the system. They made a series of small changes and adjustments to the system. For instance, they simplified a relatively complex process of validating the reports and templates generated by the finance group. At the same time, key members of the IT group conducted a series of one-to-one training sessions with the users in the operations and finance groups. This provision of additional training along with the careful modifications to the system ensured that Maxim, which was an efficient and robust to begin with, was further enhanced from a reliability and userexperience perspective.

\begin{abstract}
After the tests and validation processes were done on Maxim; it produces cleaner reports. We believe in having accurate and correct figures for analysis. (Senior Programmer, IT Group)

We invested more time in training them to use it and showing them how Maxim can promote efficiency and accuracy in their work. We found that they actually come back to us and said 'I found that useful' or 'can I get more information from the system?' So, just going the extra mile really seems to help users and that's like a ripple effect, once you get a set of users to use it, the system gets further promoted by word of mouth. (Database Administrator, IT Group)
\end{abstract}

A majority of the informants in the operations and finance groups corroborated the IT group's claim that the system was easier to use and more accurate, following the tests, modifications and the training sessions.

"After the test, you find the system is faster and neater. It is better because it is accurate and reduces the time you sleep in the office! (Head Credit Management, Finance Group) 
With the test run... people have now mastered the system. So the user acceptance testing with the IT team has actually paid off. The quality of data that we retrieved from Maxim is now very reliable. Quite different from having data from 15 countries showing stupid numbers because the system wasn't tested well enough! The system is very efficient now, the work, the investment in time in testing, the system now allows us to produce reliable and solid results in quick time. (Chief Financial Controller - African Subsidiaries, Finance Group)

\section{Dynamic nature of the IT Culture archetypes}

We found that over a period of time, the IT group's systemic intervention had a profound impact on the three IT culture archetypes. From the data it was evident that Maxim was designed and developed carefully in line with the requirements of the operations and finance group. In this sense, it had been an accurate and reliable system from the start, which obviously led to the creation of the embracing IT culture. The members within this cultural archetype became even more convinced after the modifications to the system that it simplified their everyday data analysis. Thus, the embracing IT culture believed in Maxim even more intensely after the IT group bolstered the system and addressed the perceived weaknesses.

The embracing IT culture was further strengthened as many members of the confused and the complaining IT culture archetypes started supporting the system and began using it routinely. Put differently, the embracing IT culture archetype expanded significantly at the cost of the confused and complaining IT culture archetypes. Initially, members in the confused category didn't understand the system and so, were not sure how to go about achieving accuracy and reliability from the system. Therefore, they were initially reluctant to use the system. Over time, this group of confused users became more familiar with the system, especially as they started attending the additional training sessions conducted by experienced members of the IT group. These sessions encouraged them to further engage with and explore the various functionalities of Maxim. They ultimately started using the system in an effective and efficient way. Put differently, the confused members realised that the system did offer the features and support they required and thus, moved over to the embracing category.

In the initial stages I complained about Maxim because it was not understandable to me. I did not know what they wanted to achieve with it. But I started seeing that Maxim was making my job easier, that is why I now appreciate the technology. (e-Channels Administrator, Operations Group) 
Unlike before when I was unsure of Maxim, I now appreciate the reliability and efficiency of Maxim. So I have now embraced it and use it every day. (Senior Financial Analyst - African Subsidiaries, Finance Group)

The complainers were suspicious of the system from the outset because they didn't think it was accurate and reliable. As a result, they actively looked for examples where they could point to deficiencies (e.g., omissions in the data, inaccurate results etc.). However, with the IT group making a series of helpful adjustments and modifications to Maxim, the complainers became more familiar with the system. They gradually accepted that the system was robust and that their earlier fears were misplaced. Hence, they moved into the embracing IT culture archetype.

Initially I rejected Maxim but over time when I started engaging more with it, I realised that compared to all other software I was using, Maxim is a better tool to get the job done. If I want to see my report from the beginning of the year to date, I couldn't do it with the earlier software. I needed to pick a month and use my calculator to add whatever I have. But that is not case with Maxim anymore. Maxim now gives you cumulative figures, month in, month out. That is why I just love it. I guess we were impatient with Maxim during the change process. (Financial Controller, Finance Group)

The Maxim team made some amendments to ensure that it works well. Since then, we have been using Maxim. All information, financial data are sourced from Maxim. (Senior Financial Analyst, Finance Group)

In short, these findings show users changed their behaviours towards Maxim. More generally, it highlights the dynamic nature of the IT culture archetypes created during the IT implementation process. The progressive weakening of the confused and complaining IT cultures and the corresponding strengthening of the embracing IT culture also shows how initial vision conflicts get transformed into vision agreements.

\section{Discussion}

In this section, we use culture theory to explain how and why IT culture may influence the successful implementation of an MIS. Our first research question investigated the IT culture archetypes that emerge during the implementation of IT. The findings revealed the development of three different IT cultures - embracing (individuals who strongly supported Maxim), confused (individuals who were unclear about the purpose of, or need for Maxim) and complaining (individuals who did not accept Maxim) during the implementation of the technology. It is interesting to note that the identified IT culture archetypes were not specific to the functional organisational subgroups of finance, IT and operations but consisted of 
individuals across the organisational subgroups. This is consistent with prior research that has studied the different IT culture archetypes that emerge during the implementation of IT. For example, Kaarst-Brown and Robey (1999) identified a fearful IT culture archetype where users resisted automation, assuming and arguing that machine errors were difficult to correct and that machine processing would be inaccurate. Similarly, Walsh et al., (2010) identified a passionate IT culture archetype where users assumed that they could not go about their day to day life without using IT and a disenchanted IT culture archetype who expected IT tools to fail. Our findings suggest that following the implementation of IT, managers can expect several IT culture archetypes to become salient. Users in these culture archetype groups may be pro-active in nature and facilitate the adoption of the IT within an organisation e.g. users championing technology enabled improvements in the speed of complex data analysis and generation of sophisticated management reports. Alternatively, they may exhibit more disruptive or inhibiting behaviours, e.g. complaining about inadequacies in the IT, or not using the full functional capabilities of the IT. Thus, the findings of our study indicate that different IT culture archetypes can emerge during the implementation of an IT. They also show how these archetypes can develop reasonably quickly in line with the initial user experiences of the system, despite the implementation team attributing values of reliability and integrity to the system.

Our second research question examined how IT culture influences the successful implementation of IT. Following the implementation of Maxim, one positively inclined IT culture archetype (embracing) and two negatively inclined IT culture archetypes (confused, complaining) were evident. These contrasting archetypes emerged because users in these groups were either unclear or unconvinced that Maxim could achieve the accuracy and reliability that they desired to undertake their work tasks. Over time and following additional training sessions and a series of adjustments and modifications to Maxim, members of the confused and complaining cultures became more familiar with the system and began to use it in a more effective and efficient way. Gradually, these users realised that their initial concerns were misplaced and that Maxim did offer the functionality, accuracy and reliability that they required. Thus, users in the two negatively inclined cultures moved to the embracing culture that became the dominant IT culture profile in the bank.

Walsh et al. (2010) suggest that IT users may exhibit traits of two or more IT culture profiles to form culture hybrids, usually with one dominant profile. However, these culture hybrid 
profiles may change over time depending on individual user experiences with IT and interactions with other culture hybrids. Walsh et al. (2010) describe this evolving change as 'culture creep', as a former minor IT culture profile grows to become dominant over the previously dominant profile e.g. a manager moving from a frightened archetypal profile to a disciplined archetypal profile. Our findings support the view that IT culture archetypes are dynamic. It is possible users in the confused and complaining groups may have also held a less dominant embracing IT culture archetype. Over time, the embracing culture was cultivated to become the dominant IT culture of users in these groups, leading to a successful IT implementation. The IT group was able to activate culture creep through the provision of additional training and modifications to the IT, facilitating the transition of users from negatively inclined cultural archetypes to the more positively inclined embracing archetype. Our study makes an important contribution to this debate as it indicates that remedial measures such as system modifications and additional training can be important to encourage users to transition from initial negative IT cultures to more positive embracing IT cultures, ultimately resulting in a successful system implementation. Our case brings into sharp focus the role of IT groups and departments, which develop complex MIS for intra-organisational use. In particular, it underscores the need for IT groups to closely monitor and understand how different end-users are actually using the system. Such awareness can help IT groups to make tweaks and modifications to IT systems to enhance user engagement. By contrast, a demanding and smug IT group, which blames end-users for the poor uptake of IT, can end up being of the main reasons for the confused and complaining IT cultures to dominate.

A further contribution from our study concerns the contrasting visions of a technology that can emerge after implementation. For example, the IT group had a very clear vision of Maxim as being robust, reliable and accurate. This vision was shared by the embracing IT culture group. However, the confused and complaining IT culture groups did not share this clear vision of the system, perceiving the system to be unreliable and inaccurate. Vision conflict occurs when a group's IT culture conflicts with the values embedded within a specific technology (Leidner and Kayworth 2006). Thus, for the confused and complaining groups vision conflict was evident, whereas the embracing group had vision agreement. Why do vision conflicts develop in the first place? We may offer a slightly speculative, albeit reasonable explanation based on our findings. Vision conflicts occur when users' IT culture, based on their existing extrinsic and intrinsic motivations to use an IT artefact, interacts with their developing assumptions and beliefs about the system. By contrast, the values embedded 
in an IT artefact are the values an organisation identifies to be vital to attaining its organisational objectives. Embedded values can be exemplified by Friedman et al.’s (2008) value sensitive design concept. The concept suggests that design of the IT artefact should not just be for the technology to perform tasks effectively and that it ought to clearly symbolise particular important values (e.g. trust, team working, autonomy, privacy, usability, efficiency). Thus, embedded values in IT may be different from how users' IT culture develop, resulting in vision conflict (Leidner and Kayworth 2006). Further, as our results suggest a system's positive values and features may take some time to become apparent to user groups and the process may require serious and proactive interventions from IT development teams.

Leidner and Kayworth's (2006) explanation of vision conflicts along functional and hierarchical lines highlight a sustained conflict relationship between champion and user group IT cultures. Further, they argue that a sustained conflict relationship could also lead to a change in a group's IT culture because the group might need to respond to competitive pressures, and thus decide to interact with the technology in a positive manner to remain relevant. However, our findings do not indicate the influence of such institutional pressures. They offer a rather more culturally-grounded explanation - when users' IT culture are aligned with the embedded values in IT, it helps shape positive engagement and usage of the technology, demonstrated through the creation and strengthening of the embracing IT culture during implementation (Orlikowski and Scott 2008; Qiu and Benbasat 2005). They also support Leidner and Kayworth’s (2006) argument that increased engagement with technology can influence subsequent usage of the technology despite initial user assumptions that the values embedded in the technology may be misaligned with their expectations. Thus, it would appear that IT assumptions are highly malleable and subject to the influence of experience (Kaarst-Brown and Robey, 1999). Following this logic, we suggest a dynamic change in IT cultures could happen because the formation of IT culture is largely dependent on an individual's needs and motivations. Thus, over a period of time, if individuals perceive their interactions with IT has begun to satisfy their needs, they would be motivated to use the IT, reshaping their existing IT culture.

\section{Conclusions}


This study adopted the IT culture perspective and the role of IT artefact to explore how and why IT cultures influence the successful implementation of IT. Implications for IT culture, theory and practice are discussed below.

Existing studies highlight that values embedded in a specific technology and an IT culture are often in conflict (Koch et al., 2013), which Leidner and Kayworth (2006) conceptualise as 'vision conflict'. Our study provides evidence to indicate that embedded IT values and IT cultures may also align eventually, which we conceptualise as 'vision agreement' and that degrees of both vision conflict and agreement can be evident during an IT implementation. The dynamic nature of IT culture means such IT implementations should not be simply represented as being either an inherent success or failure as there is likely to be movement of users between IT culture archetypes after implementation. Studies that allude to organisational culture or subculture to explain how users react to IT (e.g. Ravishankar et al., 2011; Rivard et al., 2011) highlight that IT implementations fail due to cultural forces that inhibit the usage levels required to facilitate successful IT implementations. Our study makes an important theoretical contribution by highlighting that identifying individuals' personal cultural dispositions toward IT can be valuable to understand why individuals react to IT, and explain how successful IT implementation can be achieved. These contributions are important because they could provide strategies for managers to achieve successful IS implementation and a return on their IS investment.

We contribute to IS practice by proposing that managers should assess the IT archetypes of potential IT users in their organisation prior to IT implementation. This IT culture audit would enable managers to assess the likely fit of the system with users' cultural values/initial assumptions and the values embedded within the IT artefact. Should the assessment reveal a misalignment between users' cultural values/initial assumptions and the IT artefact managers may choose to modify the IT or target particular individual users for additional training and support during the implementation. Further, managers can take reassurance from our study's findings that it is common for a range of IT cultures to emerge following the implementation of an IT. Some of these IT culture user groups may be positively inclined toward the new IT, but some may resist. However, so long as the IT is robust and reliable, even if some users do not recognise these attributes at the outset, IT managers can enact culture creep strategies to encourage users to transition from resisting IT cultures to embracing IT cultures.

Managers could adopt several strategies to encourage culture creep. For example, they may 
choose to make adjustments to the IT, provide specialist training to small groups, or give greater responsibility to IT-inclined individuals. If senior managers are able to give ITinclined individuals greater responsibility, this may help to promote and influence the usage and implementation of IT in their organisations. These individuals should be encouraged to be actively involved in training, education and awareness campaigns designed for promoting acceptance and usage of the technology. Such initiatives may engender social pressure (Venkatesh et al., 2003), which could help non-responsive individuals to develop more positive behaviours toward using the technology, as they see their colleagues interacting positively with the technology. Thus, over time the dynamic nature of IT culture may allow initial negative perceptions to be converted to positive views, enabling a successful IT implementation.

Notwithstanding these contributions, we highlight two key limitations of our study. First, while our study's single case study provides deep insights and increases the representativeness of the views regarding IT implementation, we acknowledge the limited generalizability of our study's findings. However, we argue that, our single case study is generalisable to theoretical statements (Lee and Baskerville, 2003) because our research contributions are grounded in empirical evidence and also supported by the extant literature. Second, the context of our study was the banking industry, a sector that has a long standing emphasis on accurate and reliable information that is well suited for technology to support. Thus, it may easier to align IT cultures and values embedded in an IT artifact in this context, than in more creative, or non-profit making industry sectors, where users may hold more contrasting IT culture values. Therefore, we recommend future studies investigate the dynamic nature of IT cultures in additional industry contexts and organisations.

\section{References}

Abubakre, M., Coombs, C. R., Ravishankar, MN. (2014), “The influence of organizational culture on the outcome of an IS implementation", in the Proceedings of the International Conference on Information Systems, Auckland, New Zealand.

Alavi, M., Kayworth, T. and Leidner, D. (2006), “An Empirical Examination of the Influence of Organizational Culture on Knowledge Management Practices”, Journal of Management Information Systems, Vol. 22 No. 3, pp. 191-224.

Alvarez, R. (2008), "Examining technology, structure and identity during an enterprise system implementation”, Information Systems Journal, Vol. 18 No. 2, pp. 203-224. 
Al-Natour, S. and Benbasat, I. (2009), "The Adoption and Use of IT Artifacts: A New Interaction-Centric Model for the Study of User Artifact Relationships”, Journal of the Association of Information Systems, Vol. 10 No. 9, pp. 661-685.

Davis, F. D. (1989), "Perceived usefulness, perceived ease of use, and user acceptance of information technology”, MIS Quarterly, Vol. 13 No. 3, pp. 319-339.

Fortune, J. and White, D. (2006), "Framing of project critical success factors by a systems model”, International Journal of Project Management, Vol. 24 No. 1, pp.53-65.

Friedman, B., Kahn Jr., P., and Borning, A. (2008), "Value Sensitive Design and Information Systems", in Himma, K. and Tavani, H. (Ed.), The Handbook of Information and Computer Ethics, Wiley, Hoboken, NJ, pp. 69-102.

Gallivan, M. and Keill, M. (2003), “The user-developer communication process: a critical case study”, Information System Journal, Vol. 13 No. 1, pp. 37-68.

Guzman, I. and Stanton, J. (2009), "IT occupational culture: the cultural fit and commitment of new information technologists”, Information Technology and People, Vol. 22 No. 2, pp. 157-187.

Jarvenpaa, S. L. and Leidner. D. E. (1998),"An Information Company in Mexico: Extending the Resouree-Based View of the Firm to a Developing Country Context," Information Systems Research, Vol. 9 No. 4, pp. 342-361.

Kaarst-Brown, M. L. and Robey, D. (1999), "More on myth, magic and metaphor: cultural insights into the management of information technology in organizations". Information Technology and People, Vol. 12 No. 2, pp. 192-217.

Koch, H., Leidner, D. E. and Gonzalez, E. S. (2013), "Digitally enabling social networks: resolving IT-culture conflict”. Information Systems Journal, Vol. 23 No. 6, pp. 501-523.

Lee, A. S. and Baskerville, R. L. (2003), "Generalizing Generalizability in Information Systems Research”, Information Systems Research, Vol. 14 No. 3, pp. 221-243.

Leidner, D. E. and Kayworth, T. (2006), "Review: a Review of Culture in Information Systems Research: Toward a Theory of Information Technology Culture Conflict”, MIS Quarterly, Vol. 30 No. 2, pp. 357-399.

Lyytinen, K. and Hirschheim, R. A. (1987), "Information Systems Failure: A Survey and Classification of The Empirical Literature", in Zorkoczy, P. I. (Ed.), Surveys in Information Technology, Oxford University Press, Oxford, pp. 257-309.

Markus, M. L. (1983), "Power Politics and MIS Implementation”, Communication ACM, Vol. 26 No. 6, pp. 430-444.

Markus, M. L. and Robey, D. (1988), "Information technology and organisational change: causal structure in theory and research”, Management science, Vol. 34 No. 5, pp. 583-598.

Martin, J. (1992), Cultures in Organizations, Oxford University Press, Oxford.

Martin, J. (2002), Organizational Culture - Mapping the Terrain, Sage, Thousand Oaks, CA.

Meyerson, D. and Martin, J. (1987), “Cultural Change: An Integration of Three Different Views”, Journal of Management Studies, Vol. 24 No. 6, pp. 623-647. 
Orlikowski, W. J. and Iacono, C. S. (2001), "Research commentary: Desperately seeking the "IT" in IT research - A call to theorizing the IT artefact”, Information Systems Research, Vol. 12 No. 2, pp. 121-134.

Orlikowski, W. J. and Scott, S. V. (2008), "Challenging The Separation Of Technology, Work and Organisation”, Academy Of Management Annals, Vol. 2 No. 1, pp. 433-474.

Patton, M. Q. (1990), Qualitative Evaluation and Research Methods, (2nd Ed), Sage Publications, Newbury Park, CA.

Patton, M. Q. (2002), Qualitative Research and Evaluation Methods, Sage Publications, Thousand Oaks, CA.

Png, I. P. L., Tan, B. C. Y. and Wee, K. L. (2001), "Dimensions of National Culture and Corporate Adoption of IT Infrastructure," IEEE Transactions on Engineering Management, Vol. 48 No. 1, pp. 36-45.

Post, G. V., Kagan, A. and Keim, R. T. (1999), “A structural equation evaluation of CASE tools attributes”, Journal of Management Information Systems, Vol. 15 No. 4, pp. 215234.

Qiu, L. and Benbasat, I. (2005), “Online consumer trust and live help interfaces: The effects of text-to-speech voice and three-dimensional avatars”, International Journal of HumanComputer Interaction, Vol. 19 No. 1, pp. 75-94.

Ravishankar, M. N., Pan, S. L. and Leidner, D. E. (2011), "Examining the Strategic Alignment and Implementation Success of a KMS: A Subculture-Based Multilevel Analysis”, Information Systems Research, Vol. 22 No. 1, 39-59.

Rivard, S., Lapointe, L. and Kappos, A. (2011), “An Organisational Culture-based Theory of Clinical Information Systems Implementation in Hospitals", Journal of the Association for Information Systems, Vol. 12 No. 2, pp. 123-162.

Ruppel. C. P. and Harrington, S. J. (2001), "Sharing Knowledge through Intranets: A Study of Organizational Culture and Intranet Implementation," IEEE Transactions on Professional Communication, Vol. 44 No. 1, pp. 37-52.

Schein, E. H. (1985), "How culture forms, develops, and changes", in Kilmann, R. H., Saxton, M. J., Serpa, R. (Ed.), Gaining Control of the Corporate Culture, Jossey-Bass, pp. San Francisco, CA, pp. 17-43.

Smircich, L. (1983), “Concepts of culture and organisational analysis”, Administrative Science Quarterly, Vol. 28 No. 3, pp. 339-358.

Siggelkow, N. (2007), "Persuasion with case studies", Academy of Management Journal, Vol. 50 No. 1, pp. 20-24.

Straub, D., Loch, K., Evaristo, R., Karahanna, E., Srite, M. (2002), “Toward a theory-based measurement of culture”, Journal of Global Information management, Vol. 13 No. 23, pp. 13-23.

Venkatesh, V., Thong, J. and Xu, X. (2012), “Consumer acceptance and use of information technology: extending the unified theory of acceptance and use of technology", MIS Quarterly, Vol. 36 No. 1, pp. 157-178. 
Venkatesh, V., Morris, M. G., Davis, G. B. and Davis, F. (2003), "User acceptance of information technology: Toward a unified view”, MIS Quarterly, Vol. 27(3), pp. 425478.

Von Meier, A. (1999), “Occupational Cultures as a Challenge to Technological Innovation”, IEEE Transaction on Engineering Management, Vol. 46 No. 1, pp. 101-114.

Walliman, N. (2008) Your Research Project ( $2^{\text {nd }}$ Ed.). Sage. Los Angeles.

Wagner, E. and Newell, S. (2011), “Changing the Story Surrounding Enterprise Systems”, in Galliers, R. and Currie, W. (Ed.), The Oxford Handbook of Management Information Systems: Critical Perspectives and New Directions, Oxford University Press, Oxford, pp. 394-414.

Walsh, I. (2014), “A strategic path to study IT use through users’ IT culture and IT needs: A mixed-method grounded theory”, Journal of Strategic Information Systems, Vol. 23 No. 2, pp. 146-173.

Walsh, I., Kefi, H. and Baskerville, R. (2010), "Managing Culture Creep: Toward a strategic model of user IT culture”, Journal of Strategic Information Systems, Vol. 19 No. 4, 257280.

Williams, M. D., Dwivedi, Y. K., Lal, B. and Schwarz, A. (2009), "Contemporary trends and issues in IT adoption and diffusion research", Journal of Information Technology, Vol. 24 No. 1, pp. 1-10.

Yin, R. K. (2009). Case Study Research: Design and Methods (4th Ed.). Sage Publications, Thousand Oaks, CA. 